\title{
Creating a Tool for Assessing Domestic Violence Risk and Impact Among TANF Clients
}

\author{
Jordan J. Steiner \\ Laura Johnson \\ Andrea Hetling \\ Hsiu-Fen Lin \\ Judy L. Postmus
}

\begin{abstract}
The Family Violence Option (FVO), a provision of the 1996 welfare legislation, allows states to waive certain program requirements for domestic violence (DV) survivors in order to protect them from danger or penalties. The absence of a standardized method for assessing risk and impact has been an impediment to states' use of the FVO, particularly in the granting of waivers. The purpose of this study was to address this limitation by developing and testing a risk and impact assessment tool for DV survivors applying for waivers under the FVO. Therefore, a collaborative effort between state administrators and researchers was formed which included input from welfare staff and DV advocates. Background research included reviews of validated risk assessments and FVO policies, as well as primary data from focus groups and surveys with staff from the state human services organization, county welfare agencies, and DV organizations. A tool was then created with 131 questions covering demographics, abuse experiences, partner access and risk, perceptions of safety, and emotional health, and piloted in four counties. Two hundred and thirty-seven completed assessments were analyzed using descriptive statistics, principal component analysis, and feedback from assessors. The final tool $(n=$ 95 items) was informed by validated evidence and frontline practice wisdom, recommended to improve FVO utilization and survivor outcomes. From this study, the authors recommend that other states seeking changes to their FVO risk assessment policy and practice explore collaborative partnerships between practitioners and researchers in order to make decisions informed by best practices and systematic research. They should also pursue cross departmental training of risk assessment tools to prevent a siloed approach to FVO implementation.
\end{abstract}

Keywords: Family Violence Option; domestic violence; Temporary Assistance for Needy Families; risk assessment

Domestic violence (DV) has negative effects on the lives of women in multiple ways. Compared to women with no DV, survivors experience more pronounced adverse physical and mental health effects (Bonomi et al., 2006), with worse negative health outcomes among female survivors as compared to male survivors (Carbone-López, Kruttschnitt, \& Macmillan, 2006). Experiences of violence can also have a negative impact on survivors'

Jordan J. Steiner, MA, MSW, LSW, is a Doctoral Candidate and Laura Johnson, PhD, MSW, LSW, is an Assistant Research Professor, Rutgers School of Social Work, New Brunswick, NJ. Andrea Hetling, PhD, is an Associate Professor, Edward J. Bloustein School of Planning and Public Policy, New Brunswick, NJ. Hsiu-Fen Lin, MA, MSW, LSW, is a Doctoral Candidate and Judy L. Postmus, PhD, ACSW, is Professor and Associate Dean for Research and Faculty Development, Rutgers School of Social Work, New Brunswick, NJ. 
financial health, ability to work, and ability to seek help, thus putting survivors at risk of experiencing poverty (Meisel, Chandler, \& Rienzi, 2003).

For some survivors, public cash assistance, or welfare, is an important support and often a means to escape an abusive relationship. Tolman and Raphael (2000) report lifetime prevalence rates of DV for welfare recipients between $50 \%$ and $60 \%$, and rates of current or recent abuse from $20 \%$ to $30 \%$. Moreover, several studies have documented the negative physical and mental health consequences of DV on survivors who are welfare recipients, demonstrating that abuse victims are more likely to report adverse physical health and increased mental health challenges than those who are not abused (Allard, Albelda, Colten, \& Cosenza, 1997; Barusch, Taylor, \& Derr, 1999). Those who struggle with stress, powerlessness, and social isolation associated with both DV and poverty may experience post-traumatic stress disorder (PTSD), depression, and other emotional difficulties (Goodman, Smyth, Borges, \& Singer, 2009).

In 1996, the Personal Responsibility and Work Opportunity Reconciliation Act (PRWORA, PL 104-193) modified the U.S. approach towards income support with Temporary Assistance for Needy Families (TANF), a time-limited and means-tested program mandating work requirements, paternity disclosure, and other conditions for recipients. Although public cash assistance is an important support and often a means to escape abusive relationships, the 1996 welfare reform sharpened the crisis of economic security among female survivors on welfare. Recognizing that DV survivors could face difficulty meeting the requirements of the 1996 welfare reform, Senators Wellstone (Democrat, $\mathrm{MN}$ ) and Murray (Democrat, WA) crafted the Wellstone/Murray Amendment to require that states screen welfare recipients for DV, refer survivors to services, and waive benefits requirements through a waiver of good cause. Before the final passage of the 1996 PROWRA, the Amendment was converted to a state "option," and adopted as the Family Violence Option (FVO, PL 104-193). Although 42 states have formally adopted the FVO and all others have implemented related services for DV survivors (Holcomb et al., 2017), utilization and implementation vary widely (An, Yoo, \& Nackerud, 2016). To be eligible for waivers under the FVO, survivors must be assessed for DV to determine which waivers are appropriate. However, no robust or standardized tool was made available to assist states in the 1990s nor has one emerged since that time. Additionally, the waiver granting process as well as who screens and assesses risk among applicants and recipients varies from stateto-state (Holcomb et al., 2017). Therefore, although the FVO policy provides necessary protections for DV survivors on welfare, it fails in policy implementation due to the lack of a validated and standardized risk assessment tool.

\section{Current Project}

In response to this lack of a standardized and robust tool for use in FVO implementation, in July 2015, the New Jersey Department of Human Services (NJ-DHS), Division of Family Development (DFD), contracted with the Center on Violence Against Women and Children at Rutgers University School of Social Work to develop, implement, and test a risk and impact assessment tool for DV survivors applying for services and waivers under the FVO. Four waivers are available to survivors in the study state, including ones from the 60-month time limit, compliance with work requirements, paternity 
disclosure for child support, and one allowing for more lenient access to emergency assistance. In order to accomplish this goal and advance significant policy change in this area, a diverse collaborative effort among the state-level administrators who sponsored the research and university researchers was formed. The project also depended on participation from DV survivors receiving TANF and staff at the county agencies and local DV organizations, contracted by the state to conduct the risk assessments.

Notably, this study provided the research team, which was comprised of faculty and students from the disciplines of social work and public policy with expertise in DV, with the opportunity to directly shape the policies and practices guiding the implementation of the FVO in New Jersey. Through this collaboration, the research team engaged in conversations with key stakeholders about the strengths and limitations of the FVO process and developed a risk assessment tool that was informed by evidence and guided by a commitment to developing an instrument that was sensitive to the unique lived experiences of the DV survivors seeking waivers. New Jersey serves as a strong case study due to its diverse and representative characteristics in relationship to the U.S. population in terms of racial and ethnic diversity, including 70\% White, 14.8\% Black, 9.8\% Asian, and 19\% Hispanic; the U.S. demographic racial and ethnic composition is similar at $76 \%$ White, 13.8\% Black, 6.1\% Asian, and 17\% Hispanic (U.S Census Bureau, 2015).

\section{Risk Assessment Tool Development: Background Research}

Data were collected from multiple sources to inform the creation of the risk assessment tool. These data sources included reviews of FVO policies and practices across the U.S., risk assessment literature within and outside the TANF program, as well as surveys and focus groups with staff from the state agency, county welfare agencies, and DV organizations.

\section{State Policy and Family Violence Option Literature Review}

To understand the implementation of the FVO across the U.S., the research team gathered information from state websites and scholarly publications. The team also communicated directly with state agencies as needed. In reviewing state policies, the team focused on eight key areas: whether or not the state has formally adopted the FVO, the definition of family violence, how states inform clients of waivers, how they screen clients, who handles referrals, who completes the risk assessment, who grants waivers, and the types of waivers available. A comprehensive review of the literature was completed to understand best practices and policies on how DV is identified and how welfare departments across the U.S. assess risk.

Findings from the review indicate that implementation of the FVO, including specific rules and assessment processes, varies across states (Holcomb et al., 2017). Moreover, based partially on the great number of decisions made by risk assessors, the literature to date does not provide a thorough evaluation or guide to best practices. Implementation decisions were based on local circumstances, including need, funding, and politics, and were found to not be solely tied to social science findings. The majority of the approaches 
to assessing risk of DV were more qualitative than quantitative in nature. As a result, we were unable to model our tool off a currently existing risk assessment in the U.S.

Research on the FVO highlights various challenges to conducting rigorous risk assessment. Hahn and Postmus (2014) discuss the importance of identifying abuse history as a first step to helping DV survivors move safely out of poverty. Although screening for DV is the first mandated step of the FVO, research suggests that survivors are being screened by frontline workers at low rates (Casey, Davies, Gifford, \& Menard, 2010; Lindhorst, Meyers, \& Casey, 2008; Postmus, 2004) and that screening behaviors differ between states, organizational structure, the nature of the encounter, and workers' length of employment (Lindhorst et al., 2008).

Even in circumstances in which frontline workers are screening for DV as part of the TANF process, there are concerns that the screening is not done sensitively or in a way as to encourage disclosure. Low rates of disclosure have been documented, with estimates of disclosure rates between 1\% to 3\% (Saunders, Holter, Pahl, Tolman, \& Kenna, 2005) and $10 \%$ (Lein, Jacquet, Lewis, Cole, \& Williams, 2001). Based on findings from a longitudinal study, Meisel and colleagues (2003) suggested that the disparity between the high percentage of serious abuse prevalence within their sample of survivors and the very low percentage of waiver use may be indicative of problems with the identification of survivors within the welfare system. Survivors may also be reluctant to disclose the abuse due to concerns about how the disclosure will be perceived and responded to, with one study finding that TANF workers breached clients' confidentiality and disclosed private information to the clients' abusers (Casey et al., 2010). In an examination of the FVO in Maryland, Hetling, Saunders, and Born (2006) found that women of color and those with less education are less likely to disclose DV to their caseworkers.

Given these limitations, Hahn and Postmus (2014) suggested providing TANF frontline workers with comprehensive training on the dynamics of DV, helpful assessment tools, and information about agency and community resources. Further, Cole (2001) discusses the need to understand how families and communities view survivors who leave their partners, as this is important in assisting them with risk assessments and future plans. There is thus an expressed need for sensitivity to individuals' circumstances, as well as space for advocacy, within the risk assessment process (Postmus, 2000). Other scholars offer suggestions on how to improve the FVO waiver process. These recommendations include removing sanctions, screening every applicant for DV, and referring survivors for mental health services as appropriate (Laakso \& Drevdahl, 2006). Meier (1997) suggests that developing "objective" (p. 242) and scientific measures of screening might improve the screening process, but cautions around the risk of stigma and pathologization.

\section{Review of Risk Assessment Literature}

Assessment and management of risk are critical components of the DV intervention process. Building on the recommendation of Meier (1997) for a more rigorous risk assessment measure in the FVO process, the research team conducted a comprehensive review of the DV risk assessment literature. The overarching goal of this literature review was to report on existing risk assessments used by DV providers to determine what, if any, 
could be adapted for use in the FVO process. The research team first documented the general process of assessing DV risk. Overall, the process includes identifying risk factors, deciding on a method for measuring/scoring risk factors, creating a procedure to combine scores, and constructing the estimated risk of violence (Monahan \& Skeem, 2014). The review covered three different types of risk assessment methods: unstructured clinical judgment (decision-making), actuarial assessments, and structured professional judgment (Kropp, 2008).

Unstructured clinical judgment or decision-making is the more traditional method of a DV risk assessment. As part of unstructured clinical judgement, the risk assessor relies on his or her professional qualifications, experience, and discretion to determine survivor risk for future abuse. Concerns around this methodology are centered on lack of reliability, validity, and accountability (Kropp, 2008). Actuarial methods of risk assessment are structured to predict specific behaviors using statistical models and formulas based on previous research to provide a probability of future violence. These actuarial methods have been criticized for their lack of practical utility, as they diminish professional discretion, do not inform practitioners about specific violence prevention strategies, and often include measurement error (Kropp, 2008). The third method of risk assessment, structured professional judgment, strives to create a balance between the previous two. This method uses professional guidelines to set a minimum of risk factors for consideration while also incorporating experiential knowledge (Kropp, 2008; Nicholls, Pritchard, Reeves, \& Hilterman, 2013).

The following questions guided the literature review: a) What is theoretically/empirically known about existing risk assessments used by DV organizations?, b ) How is risk assessed in other similar contexts?, c) How do existing risk assessments capture multiple forms of violence?, and d) What outcomes are associated with different approaches to risk assessments? With these questions in mind, the research team systematically reviewed academic databases and found that most risk assessments were perpetrator-focused, including such assessments as the Domestic Violence Screening Instrument (DVSI; Stansfield \& Williams, 2014), and the Brief Spousal Form for Evaluation of Risk (B-SAFER; Storey, Kropp, Hart, Belfrage, \& Strand, 2014), with minimal DV survivor-oriented risk assessments.

Findings from the risk assessment review suggest that existing unstructured clinical assessments aligned with the purpose of assessments in the TANF context, but lacked validity and reliability. Additionally, while existing actuarial assessments demonstrated validity, such tools were less practical in the context of DV risk assessments related to welfare and the FVO. Most existing risk assessments focused on predicting re-assault, severe violence, or lethal violence committed by perpetrators (e.g., Campbell, Webster, \& Glass, 2009; Echeburúa, Fernández-Montalvo, de Corral, \& López-Goñi, 2009; Messing $\&$ Thaller, 2014). These assessments were most commonly developed for use within the criminal justice system to assess for the likelihood of recidivism. Risk assessments have also been used within clinical settings to help survivors to develop safety plans (e.g., Campbell, 2004; Echeburúa et al., 2009). Although existing scales on DV capture multiple forms of abuse, there is no existing comprehensive risk assessment from a survivor perspective that is also related to welfare determinations. 
One risk assessment tool with potential relevance to the FVO process was the Danger Assessment (DA; Campbell, 2004). The DA was developed to assist with the clinical prediction of lethality as well as guide intervention strategies (Campbell, 1995). DA items were thus incorporated into the FVO risk assessment developed by the research team. However, because the tool assesses for lethality alone, it is not sufficiently comprehensive for the FVO process.

\section{Key Stakeholder Survey}

As a next stage in the data-gathering process, key stakeholders from the county welfare agencies, DV organizations, and the NJ-DFD were surveyed to assess their attitudes and beliefs related to the FVO process $(n=135)$. Potential survey participants were recruited through key contacts at the NJ-DFD and the New Jersey Coalition to End Domestic Violence (NJCEDV) who assisted with distributing the survey to organizational staff. The population sample size was not tracked, as the goal was just to gather feedback from as many key stakeholders as possible. The survey tool included seven scales asking about participants' attitudes on the state's TANF program and waivers; beliefs about the causes of DV; the relationship between county welfare agencies and DV organizations within New Jersey; the perceived effectiveness of risk assessments; and professional confidence working with survivors. In addition, participants were asked questions about their personal experiences with welfare benefits and DV, as well as demographic questions. Overall, participants included NJ-DFD representatives $(n=4)$, county-level welfare employees $(n=79)$, and DV organization staff $(n=52)$. Analyses were conducted in SPSS version 23.

The demographic characteristics of the survey participants are presented in Table 1 and are also divided out by work agency. Overall, the majority of participants $(80.0 \%)$ identified as female and almost half (45.2\%) identified as white. A Bachelor's degree was held by approximately $39 \%$ of those surveyed, with around $40 \%$ holding a master's degree. Approximately half were between the ages of 31-40 (25.9\%) or 51-60 (26.7\%). Survey participants were also asked questions about their personal experiences with DV and welfare benefits, either about themselves or people they know. They answered "yes," "no," or "unsure" for each of the statements.

More than three-fourths of participants (77.4\%) knew someone personally who had experienced DV, although less than half $(38.7 \%)$ had experienced DV themselves. While the majority of participants $(75.9 \%)$ knew someone who received welfare benefits, only a small percentage $(10.9 \%)$ of participants had personally received welfare benefits. Of primary importance, survey participants acknowledged that the risk assessment tool should consider multiple types of abuse. In response to this, the research team chose to make the risk assessment tool comprehensive by covering all forms of DV (psychological, financial, physical, and sexual, along with stalking).

\section{Focus Groups with Key Stakeholders}

In-depth focus groups were also conducted with various stakeholders who were recruited through key contacts at the NJ-DFD and the state DV coalition. These key contacts sent emails to eligible staff members about the research study; those interested 
contacted the research project coordinator to participate in a one-time focus group. Eight focus groups were conducted - two with NJ-DFD representatives $(n=7)$, three with countylevel welfare employees $(n=19)$, and three with DV organization staff $(n=22)$. Inductive thematic analysis was used to identify key patterns within the data (Braun \& Clarke, 2006) using the qualitative data analysis program NVivo 10.

The demographic characteristics of the focus group participants are also presented in Table 1 and are divided out by work agency. Almost all participants (97.9\%) identified as female and over two-thirds (68.8\%) identified as White, with $29 \%$ identifying as Black, and $23 \%$ identifying as Hispanic. About $38 \%$ of focus group participants were between the ages of 41 and 50, and $27 \%$ between 51 and 60 . The focus groups served as a great source of information and largely informed the creation of the risk assessment tool. The themes identified centered on levels of risk and the process of recommending waivers. Participants noted a lack of understanding of how each level of risk is defined, as well as how levels of risk relate to particular waivers. County welfare agency staff members indicated that they did not understand how risk assessors, who are DV advocates tasked with implementing the FVO risk assessment, come to determine clients' level of risk and make recommendations to county welfare agency staff on which waivers survivors should receive. DV organization staff members also felt that the prior risk assessment tool was too subjective. Finally, key stakeholders acknowledged that waivers are granted on an "all or nothing" basis, meaning that clients are typically granted either all waivers or none at all. 
Table 1. Key Stakeholder Sample Characteristics

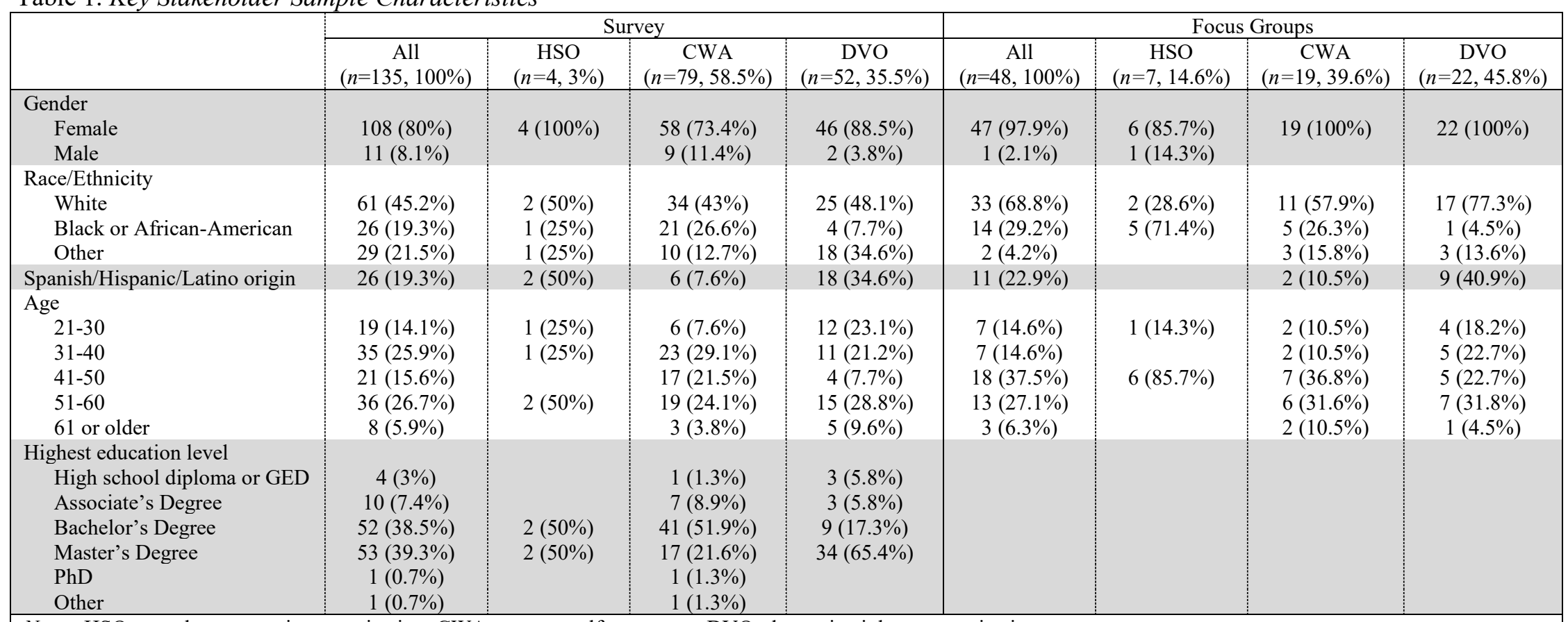

Notes. $\mathrm{HSO}=$ state human service organization; $\mathrm{CWA}=$ county welfare agency; $\mathrm{DVO}=$ domestic violence organization.

Percentages do not add up to $100 \%$ due to missing data. Only survey participants were asked their highest education level. Race/ethnicity categories were not mutually exclusive. 


\section{Initial Risk Assessment Tool Development}

The data collected through the comprehensive policy and literature reviews, surveys, and focus groups greatly informed the overall structure and content of the risk assessment tool. The research team structured the tool to be primarily quantitative in nature, with strategically placed open-ended questions to allow survivors a space to include information that was otherwise missed previously. The research team determined that the risk assessment should include risk of abuse as well as impact of abuse and that this should be measured using instruments validated with DV survivors where possible.

To create a comprehensive assessment tool, the research team reviewed existing tools and validated measures used with survivors and/or perpetrators to determine whether the questions in these tools were suitable for use in the abuse risk and impact assessment process. In other areas of the risk and impact assessment tool, the research team created new questions based on feedback from the focus groups and surveys. As part of the risk assessment development process, the research team focused on survivors' abuse experiences along with the possible impact of abuse, as this is the focus of the FVO. The researchers also recognized that the function of the risk assessment was to determine whether engaging in work activities as part of TANF would put survivors at risk for further abuse. Relationship factors and abuser attributes might aggravate or mitigate potential risk. As a result, known risk factors for future abuse were also included in the risk assessment. Lastly, the research team considered it important to consider survivor perceptions of safety as a factor that may influence how comfortable a survivor feels engaging in work activities. The development of a more standardized approach made the risk assessment tool less subjective; yet, the partner risk, partner access, and perception of safety questions, along with the open-ended questions, provided risk assessors with important background information to guide them in making recommendations for waivers for clients whose scores indicate a moderate or higher level of risk.

Ultimately, the research team created a pilot tool with 131 questions divided into six sections: 1) Demographics; 2) Abuse Experiences (including emotional, financial, physical, stalking, and sexual abuse); 3) Partner Access; 4) Partner Risk; 5) Perceptions of Safety; and 6) Emotional Health (depression, anxiety, PTSD, and substance abuse). The pilot tool was then translated into Spanish by the NJ-DFD so that an English and Spanish tool were available for use.

Emotional abuse. This section asked the client about their experiences with emotional abuse. Questions included in this section were adapted from the validated Danger Assessment (Campbell et al., 2009) and the Abusive Behavior Inventory-R (ABI-R; Postmus, Stylianou, $\&$ McMahon, 2016). Clients were asked to indicate how often in the past six months their abuser engaged in the following behaviors by indicating 0 (never) to 4 (very often) or yes/no depending on the question structure. Overall, 11 items came from the 25-item $A B I-R$ and two items came from the 19-item Danger Assessment.

Financial abuse. This section asked the client about their experiences with financial abuse and is based on the validated Scale of Economic Abuse-12 (Postmus, Plummer, \& Stylianou, 2016). Clients were asked to indicate how often in the past six months their abuser engaged in the following behaviors by indicating 0 (never) to 4 (very often) or yes/no (4) 
depending on the question structure. All 12 items from the Scale of Economic Abuse-12 were used, along with three items developed by the research team.

Physical abuse. Overall, nine items were adapted from the $A B I-R$ (Postmus, Stylianou, $\&$ McMahon, 2016) and five items were adapted from the Danger Assessment (Campbell et al., 2009). Two items were developed by the research team for the purpose of the risk and impact assessment tool. Clients were asked to indicate how often in the past six months their abuser engaged in the following behaviors by indicating 0 (never) to 4 (very often) or yes/no depending on the question structure.

Stalking. This section asked the client about their experiences with stalking and was based on questions from the National Intimate Partner and Sexual Violence Survey (U.S. Centers for Disease Control and Prevention, 2010). Clients were asked to indicate how often in the past six months their abuser engaged in the following behaviors by indicating 0 (never) to 4 (very often). All seven items came from this tool.

Sexual abuse. This section asked the client about their experiences with sexual abuse; questions were adapted from the Severity of Violence Against Women Scale (Marshall, 1992; Thompson, Basile, Hertz, \& Sitterle, 2006) and the ABI-R (Postmus, Stylianou, \& McMahon, 2016). Clients were asked to indicate how often in the past six months their abuser engaged in the following behaviors by indicating 0 (never) to 4 (very often) or yes/no depending on the question structure. Overall, three items came from the $A B I-R$ and two items came from the Severity of Violence Against Women Scale.

Partner access. This section was designed to gauge the level of access the abuser had to the client. These were generally yes/no questions that centered on current relationship status, the abuser's current residence, and restraining order status. The questions in this section did not go towards the client's score on the waiver recommendation guide; rather this information was intended to help in final considerations when recommending waivers.

Partner risk. This section looked at factors associated with abusers' lethality risk in DV situations using questions adapted from the validated Danger Assessment (Campbell et al., 2009). Clients were asked to respond yes/no to questions regarding their abusers' behaviors during the past six months. All three items came from the Danger Assessment. As with the questions in the Partner Access section, these questions did not go towards the client's score, but rather were intended to help in final considerations when recommending waivers.

Perceptions of safety. This section looked at clients' perceptions of safety within their communities, particularly in relation to fear of their abusers based on questions from the Safety Rating Scale (Culbertson, Vik, \& Kooiman, 2001) and the Violence Against Women Survey (Macmillan et al., 2000). Clients were asked to indicate how safe they felt from 0 (always safe) to 4 (not safe at all) in a series of situations. While there was some overlap between the two surveys, approximately seven items came from the Safety Rating Scale and two came from the Violence Against Women Survey. The remaining six items were adapted for the risk and impact assessment tool. These questions also did not go towards scores on the waiver recommendation guide and were included for consideration.

Depression. This section asked the client about feelings and behaviors associated with depression and the questions came from the validated 20-item Center for Epidemiological 
Studies Depression Scale (Radloff, 1977). Clients were asked to indicate how often they experienced the listed feelings and behaviors during the past two weeks by indicating whether the feelings or behaviors occurred 0 (not at all) to 3 (nearly every day).

Anxiety. This section asked the client about feelings and behaviors associated with anxiety and the questions came from the validated Generalized Anxiety Disorder-7 (Spitzer, Kroenke, Williams, \& Lowe, 2006). Clients were asked to indicate how often they experienced the seven listed feelings and behaviors during the past two weeks by indicating whether the feelings or behaviors occurred 0 (not at all) to 3 (nearly every day).

Post-Traumatic Stress Disorder. This section asked the client about feelings and behaviors associated with Post-Traumatic Stress Disorder (PTSD). The questions came from the validated PTSD-8: A Short PTSD Inventory (Hansen et al., 2010). Clients were asked to indicate how often they experienced eight feelings and behaviors during the past two weeks by indicating whether the feelings or behaviors occurred 0 (not at all) to 3 (nearly every day). Symptoms referenced in this scale fell into one of three categories, intrusion (four items), avoidance (two items), and hypervigilance (two items). Participants needed to experience at least one symptom from each category for more than half of days or greater to meet the criteria for PTSD (Hansen et al., 2010).

Substance use. This section asked the client about feelings and behaviors associated with substance use. The questions came from the validated CAGE Questionnaire (Ewing, 1984). Clients were asked to respond yes/no to whether they experienced the four listed feelings and behaviors during the past two weeks. These questions were not intended to be used for diagnostic purposes but rather to gauge the emotional impact of the clients' substance use experiences. This section was only one part of a comprehensive assessment of possible emotional impact of abuse, to mitigate victim blaming and denial of waivers based on responses. Table 2 outlines the measures that were included in both the pilot and final versions of the risk assessment tool.

To avoid the "all or nothing" predicament indicated by the focus groups, the research team developed a "score sheet," or waiver recommendation guide, to assist risk assessors in determining whether risk or impact is low, moderate, or high, as well as which waivers could correspond with each type and level of risk and impact. As a result, the decision was made to use three levels (i.e., low, moderate, high). The guide was designed to help risk assessors tease out which waivers would be most appropriate for a client given their current situation. The research team drew on their expertise in DV (based on research and practice experience) along with the academic literature to identify these three categories of risk. For example, the research team recognized that certain types of abuse (e.g., physical) pose a greater risk for a survivor in terms of likelihood of future injury and health-associated impacts. As such, survivors received a greater risk level score for having experienced physical abuse, stalking, and sexual abuse in comparison to psychological and financial abuse. 
Table 2. Scales in Pilot and Final Versions of Risk Assessment Tool*

\begin{tabular}{|c|c|c|c|c|c|}
\hline \multirow{2}{*}{$\begin{array}{l}\text { Risk/Impact } \\
\text { Area }\end{array}$} & \multirow[b]{2}{*}{ Scale Name \& Authors } & \multirow[b]{2}{*}{ Sample Item } & \multirow[b]{2}{*}{ Response Structure } & \multicolumn{2}{|c|}{ \# of Items** } \\
\hline & & & & Pilot & Final \\
\hline \multirow{2}{*}{$\begin{array}{l}\text { Emotional } \\
\text { Abuse }\end{array}$} & Danger Assessment (Campbell et al., 2009) & "Controlled most or all of your daily activities" & \multirow{2}{*}{$\begin{array}{l}0 \text { (never) to } 4 \text { (very } \\
\text { often }) \text { or } \\
0(\text { no }) / 4 \text { (yes) }\end{array}$} & \multirow[t]{2}{*}{13} & \multirow[t]{2}{*}{13} \\
\hline & $\begin{array}{l}\text { Abusive Behavior Inventory - Revised (ABI-R; Postmus, } \\
\text { Stylianou, \& McMahon, 2016) }\end{array}$ & "Called you a name and/or criticized you" & & & \\
\hline \multirow[t]{2}{*}{$\begin{array}{l}\text { Financial } \\
\text { Abuse }\end{array}$} & $\begin{array}{l}\text { Scale of Economic Abuse-12 (Postmus, Plummer, \& } \\
\text { Stylianou, 2016) }\end{array}$ & "Demanded to know how money was spent" & \multirow{2}{*}{$\begin{array}{l}0 \text { (never) to } 4 \text { (very } \\
\text { often }) \text { or } \\
0(\text { no }) / 4 \text { (yes) }\end{array}$} & \multirow[t]{2}{*}{15} & \multirow[t]{2}{*}{16} \\
\hline & $\begin{array}{l}\text { New Jersey Assessment of Domestic Violence Risk and } \\
\text { Impact (NJADVRI; Postmus et al., 2017) }\end{array}$ & "Gotten in trouble at a job because of the abuse" & & & \\
\hline \multirow[t]{3}{*}{$\begin{array}{l}\text { Physical } \\
\text { Abuse }\end{array}$} & Danger Assessment (Campbell et al., 2009) & $\begin{array}{l}\text { "Has the severity or frequency of the violence increased over } \\
\text { the past year?" }\end{array}$ & \multirow{3}{*}{$\begin{array}{l}0 \text { (never) to } 4 \text { (very } \\
\text { often }) \text { or } \\
0(\text { no }) / 4 \text { (yes) }\end{array}$} & \multirow[t]{3}{*}{16} & \multirow[t]{3}{*}{13} \\
\hline & ABI-R (Postmus, Stylianou, \& McMahon, 2016) & "Threatened to hit or throw something at you" & & & \\
\hline & NJADVRI (Postmus et al., 2017) & "If yes, was the weapon a gun?" & & & \\
\hline Stalking & $\begin{array}{l}\text { National Intimate Partner and Sexual Violence Survey } \\
\text { (U.S Centers for Disease Control and Prevention., 2010). }\end{array}$ & "Made unwanted phone calls to you or left you messages" & $\begin{array}{l}0 \text { (never) to } 4 \text { (very } \\
\text { often) }\end{array}$ & 7 & 5 \\
\hline $\begin{array}{l}\text { Technology } \\
\text { Abuse }\end{array}$ & $\begin{array}{l}\text { Cyber Dating Abuse Scale (Zweig, Dank, Lachman, \& } \\
\text { Yahner, 2014) }\end{array}$ & "Used your social networking account without permission" & $\begin{array}{l}0 \text { (never) to } 4 \text { (very } \\
\text { often) }\end{array}$ & 0 & 8 \\
\hline \multirow[t]{2}{*}{$\begin{array}{l}\text { Sexual } \\
\text { Abuse }\end{array}$} & $\begin{array}{l}\text { Severity of Violence Against Women Scale (Marshall, } \\
\text { 1992; Thompson, Basile, Hertz, \& Sitterle, 2006) }\end{array}$ & "Demanded sex whether you wanted it or not" & \multirow{2}{*}{$\begin{array}{l}0 \text { (never) to } 4 \text { (very } \\
\text { often }) \text { or } \\
0(\text { no }) / 4 \text { (yes) }\end{array}$} & \multirow[t]{2}{*}{5} & \multirow[t]{2}{*}{4} \\
\hline & ABI-R (Postmus, Stylianou, \& McMahon, 2016) & "Pressured you to have sex in a way you didn't like or want" & & & \\
\hline \multirow{3}{*}{$\begin{array}{l}\text { Perceptions } \\
\text { of Safety }\end{array}$} & Safety Rating Scale (Culbertson et al., 2001) & "How safe do you feel in your home?" & \multirow{3}{*}{$\begin{array}{l}0 \text { (always safe/NA) } \\
\text { to } 4 \text { (not safe at } \\
\text { all) }\end{array}$} & \multirow[t]{3}{*}{15} & \multirow[t]{3}{*}{7} \\
\hline & $\begin{array}{l}\text { Violence Against Women Survey (Macmillan, Nierobisz, } \\
\& \text { Welsh, 2000) }\end{array}$ & $\begin{array}{l}\text { "How safe do you feel taking public transportation during the } \\
\text { day?" }\end{array}$ & & & \\
\hline & NJADVRI (Postmus et al., 2017) & "How physically safe do your feel from your partner today?" & & & \\
\hline Depression & $\begin{array}{l}\text { Center for Epidemiological Studies Depression (CES-D) } \\
\text { Scale (Radloff, 1977) } \\
\text { CESD-Revised (CESD-R; Van Dam \& Earleywine, 2011) }\end{array}$ & "Felt bothered by things that usually don't bother you" & $\begin{array}{l}0 \text { (not at all) to } 3 \\
\text { (nearly every day) }\end{array}$ & 20 & 10 \\
\hline Anxiety & Generalized Anxiety Disorder-7 (Spitzer et al., 2006) & "Feeling nervous, anxious or on edge" & $\begin{array}{l}0 \text { (not at all) to } 3 \\
\text { (nearly every day) }\end{array}$ & 7 & 6 \\
\hline PTSD & PTSD-8: A Short PTSD Inventory (Hansen et al., 2010) & "Recurrent thoughts or memories of the abuse" & $\begin{array}{l}0 \text { (not at all) to } 3 \\
\text { (nearly every day) }\end{array}$ & 8 & 8 \\
\hline \multirow[t]{2}{*}{$\begin{array}{l}\text { Substance } \\
\text { Use }\end{array}$} & $\begin{array}{l}\text { Detecting alcoholism: The Cut Annoyed Guilty Eye } \\
\text { Questionnaire (CAGE; Ewing, 1984) }\end{array}$ & $\begin{array}{l}\text { "Have you ever felt you out to cut down on your drinking or } \\
\text { drug use?" }\end{array}$ & \multirow{2}{*}{$\begin{array}{l}0 \text { (not at all) to } 3 \\
\text { (nearly every day) } \\
\text { or } \\
0(\text { no }) / 4(\text { yes })\end{array}$} & \multirow[t]{2}{*}{4} & \multirow[t]{2}{*}{5} \\
\hline & NJADVRI (Postmus et al., 2017) & $\begin{array}{l}\text { "In the last two weeks, how often did you drink alcohol or use } \\
\text { drugs?" }\end{array}$ & & & \\
\hline
\end{tabular}


To clarify the process for completing the assessment and making recommendations on waivers, the following steps were involved. First, following each section of the risk assessment tool, space was provided to tally the score for each section. This was completed by adding the cumulative scores in each column. At the conclusion of the risk assessment, risk assessors used the waiver recommendation guide to determine the client's weighted score, overall level of risk, and which waivers to recommend. This included the process of converting the client's total score to a weighted risk level score. Thus, a low cumulative risk score was associated with no waivers and a high cumulative risk score was associated with all waivers. For clients with moderate scores, the assessor could decide which waivers to recommend. Therefore, on the waiver recommendation guide certain sections of the risk assessment tool are weighted greater than others.

Moreover, concerning impact, at the conclusion of the emotional impact section, there were also waiver guidelines. This allowed risk assessors to use the overall total impact level score to determine their client's cumulative impact level. Each cumulative impact level was associated with a waiver recommendation. Thus, a low cumulative impact score was associated with no recommended waivers and a high cumulative risk score was associated with a recommendation for all waivers except for child support cooperation. For moderate scoring clients, which waivers to recommend was made at the discretion of the risk assessor.

\section{Piloting of Risk Assessment Instrument}

The new risk assessment tool was piloted in four counties in New Jersey between June and December 2016. These counties were selected based on their perceived commitment to the study as evidenced by focus group participation, the number of risk assessments conducted during a one-quarter period, and diversity in the location and population of the county. Each county that agreed to participate in the pilot received a three-hour training on the risk assessment tool, conducted by two members of the research team. The training was attended by both DV advocates in selected counties and county welfare workers. The training provided an overview of the materials that informed the creation of the risk assessment tool. Thus the staff from the DV organizations and county welfare agencies were given an opportunity to see how their participation in the focus groups and surveys informed the first draft of the risk assessment tool. Additionally, each section of the tool was reviewed in detail to clarify and review each question and the response options. Trainees were taught to score the assessment using the waiver recommendation guide.

Overall, 237 face-to-face risk assessments were completed, ranging from 19 to 91 in each county. On average, the tool took between 45 and 60 minutes to complete. During the pilot phase, risk assessors reported that the previous risk assessment tool took between 60 to 120 minutes to complete. As such, the tool that was piloted was expected to be shorter. Further, clients completed the assessment as part of a scheduled appointment with the risk assessor. The research team collected the completed assessments from the DV organizations approximately once a month and entered them into SPSS. For confidentiality purposes, no names were associated with the risk assessments. 


\section{Analysis of Pilot Risk Assessment Tool}

The risk assessments were analyzed using descriptive statistics and principal component analysis (PCA). Descriptive characteristics of the clients who completed the risk assessment are presented in Table 3. Almost three-fourths (73.1\%) of the risk assessments completed during the pilot study were new risk assessments; the remaining were re-assessments, which occur every six months after an initial assessment is completed. Similarly, three-fourths $(75.5 \%)$ of participants identified their abuser as a former partner; $16.5 \%$ identified their abuser as a current partner; and the remaining identified their abuser as a family member $(4.2 \%)$ or other individual $(3.8 \%)$. The majority of participants identified as either Black or African American $(40.1 \%)$ or White, nonHispanic (30.4\%). Half of participants were between the ages of 26 and 35 (48.9\%) and $86.5 \%$ were responsible for at least one child. Almost $40 \%$ of participants had earned their high school diploma or GED while nearly $40 \%$ attended some college or were college graduates.

Table 3. Survivor Characteristics $(n=237)$

\begin{tabular}{|l|r|}
\hline Characteristic & \multicolumn{1}{|c|}{$\mathrm{n}(\%)$} \\
\hline Risk assessment status & $173(73.1 \%)$ \\
New risk assessment & $64(26.9 \%)$ \\
Re-assessment & $179(75.5 \%)$ \\
\hline Relationship to abuser & $39(16.5 \%)$ \\
Former partner & $10(4.2 \%)$ \\
Current partner & $9(3.8 \%)$ \\
Family member & \\
Other & $95(40.1 \%)$ \\
\hline Race/Ethnicity & $72(30.4 \%)$ \\
Black or African-American & $39(16.5 \%)$ \\
White, Non-Hispanic & $30(12.7 \%)$ \\
Latina or Hispanic & $54(22.8 \%)$ \\
Other & $116(48.9 \%)$ \\
\hline Age & $46(19.4 \%)$ \\
Less than 25 & $18(7.6 \%)$ \\
\hline 26-35 & $205(86.5 \%)$ \\
36-45 & $52(21.9 \%)$ \\
46 or older & $92(38.8 \%)$ \\
\hline Financially responsible for children, \% yes & missing data. \\
\hline Highest education level & \\
Less than high school & \\
High school diploma or GED & \\
Some college or college graduate & \\
\hline Note. Percentages do not add up to 100\% due & \\
\hline & \\
\hline
\end{tabular}

The research team used PCA to create a shorter version of the risk assessment tool and to identify critical items with the most explanatory power. PCA is a type of statistical technique that identifies patterns within a dataset with the goal of extracting the variables 
with the most important information and can be used for data reduction by identifying items that are not important or repetitive (Abdi \& Williams, 2010). In other words, PCA is used to combine variables that account for the most total variation in the data and to eliminate the least important items. PCA creates new variables, called principal components, to transform the original variables into linear combinations. The first principal component retains the largest possible variance explained, and each succeeding component accounts for the remaining variance (Abdi \& Williams, 2010). The research team did not name the components, as the only function of the analysis was to determine whether any items could be reduced. To determine whether variables can be reduced, researchers must first look collectively at the total variance explained, the correlations to determine whether any items are highly correlated, and the strength of individual loadings on each component. For example, Maiuro and colleagues (2000) developed a health provider survey for domestic violence with an initial pool of 104 items, and used PCA to identify which items clustered together and dropped items with loadings of greater than 0.50 on the main components, resulting in 39 items for practice use.

In this study, PCA was used for all of the abuse scales from the abuse experiences section (i.e., emotional, financial, physical, stalking, sexual), as well as with two of the four scales to measure impact (i.e., anxiety, PTSD). This is referred to in Table 4, which outlines the critical areas of the PCA (See Postmus et al., 2017 for additional information on PCA results for all scales). PCA was not used to analyze items in the partner access, partner risk, and substance use sections because these were nominal data. PCA was also not used to analyze items in the perceptions of safety scale because these questions did not go towards the client score on the waiver granting guide, but rather was intended to help in final consideration of waivers. Additionally, PCA was not used to test the depression scale, as the decision had already been made to use the shorter 10-item version for the final instrument. This 10-item version was based on the CESD-R scale (Van Dam \& Earleywine, 2011), as a result of informal feedback received from the risk assessors.

Table 4. Principal component analysis of seven risk and impact scales

\begin{tabular}{l:c:c:c:c:c}
\hline Risk/Impact Area & $\begin{array}{c}\text { \# of Items } \\
\text { Tested }\end{array}$ & $\begin{array}{c}\text { \# of } \\
\text { Components }\end{array}$ & $\begin{array}{c}\text { Cumulative \% } \\
\text { of Variance }\end{array}$ & $\begin{array}{c}\text { Factor } \\
\text { Loadings }\end{array}$ & $\begin{array}{c}\text { \# of items } \\
\text { after PCA }\end{array}$ \\
\hline Emotional Abuse & 13 & 2 & 56.5 & $.46-.78$ & 13 \\
Financial Abuse & 15 & 3 & 66.9 & $.50-.78$ & 14 \\
Physical Abuse & 16 & 3 & 58.5 & $.35-.82$ & 15 \\
Stalking & 7 & 2 & 56.3 & $.50-.81$ & 6 \\
Sexual Abuse & 5 & 1 & 68.6 & $.73-.92$ & 4 \\
Anxiety & 7 & 1 & 62.8 & $.70-.86$ & 6 \\
PTSD & 8 & 1 & 57.5 & $.67-79$ & 8 \\
\hline
\end{tabular}

Note. PCA was not conducted on scales with nominal data (partner access, partner risk, and substance abuse questions), therefore, these items did not contribute to the client score on the waiver-granting guide (perceptions of safety scale) but rather were intended to help in final consideration of waivers, or scales where an abbreviate version of the measure already existed (depression scale).

To perform the PCA across seven scales, the research team first examined the correlation matrix among items in each scale. The majority of correlation coefficients were above 0.3, indicating the appropriateness for PCA (Tabachnick \& Fidell, 2013). Second, 
Bartlett's test of sphericity was significant within all scales. The Kaiser-Meyer-Olkin measure of sampling adequacy ranged from 0.778 to 0.924 , between the commonly recommended value above 0.6, showing the sampling was adequate (Streiner, Norman, \& Cairney, 2015). Third, the communalities were all above 0.3, indicating that the items shared some common variance. Finally, the subject-to-item ratios spanned from 18:1 to 47:1 (Osborne \& Costello, 2004). These overall indicators showed the PCA was suitable for data extraction.

Emotional Abuse Scale. First, a PCA was run on the 13-item Emotional Abuse scale. PCA revealed two components that had eigenvalues greater than one, which cumulatively explained $56.5 \%$ of the total variance. Assessment of the correlation and component matrices suggested that the items in the scale were strong and thus, none were removed.

Financial Abuse Scale. A PCA on the 15-item Financial Abuse Scale revealed three components with eigenvalues greater than one, which cumulatively explained $66.9 \%$ of the total variance. The items "Demanded to know how money was spent" and "Demanded that you give them receipts and/or change when you spent money" had a high positive correlation. As a result, these two questions were merged and the item was changed to "Demanded to know how money was spent" (for example, "Demanded that you give them receipts").

Physical Abuse Scale. A PCA on the 16-item Physical Abuse Scale revealed three components with eigenvalues greater than one, which cumulatively explained $58.5 \%$ of the total variance. The items "Threw you around" and "Choked or strangled you" had a high positive correlation. As a result, the item "Threw you around" was removed.

Stalking Scale. A PCA on the 7-item Stalking Scale revealed two components with eigenvalues greater than one, which cumulatively explained $56.3 \%$ of the total variance. The item "Left you cards, letters, flowers, or presents when your abuser knew you didn't want them" was found to contribute minimally to the scale; therefore, the item was removed.

Sexual Abuse Scale. A PCA on the 5-item Physical Abuse Scale revealed one component with an eigenvalue greater than one, which cumulatively explained $68.6 \%$ of the total variance. The items "Demanded sex whether you wanted it or not" and "Pressured you to have sex in a way that you didn't like or want" had a high positive correlation. Therefore, these items were merged to, "Pressured you to have sex when you didn't want to or in a way that you didn't like or want."

Anxiety Scale. A PCA on the 7-item Anxiety Scale revealed one component with an eigenvalue greater than one, which cumulatively explained $62.8 \%$ of the total variance. The items "Not being able to stop or control worrying" and "Worrying too much about different things" were found to have a high positive correlation so the item "Not being able to stop or control worry" was removed.

PTSD Scale. A PCA on the 8-item PTSD Scale revealed one component with an eigenvalue greater than one, which cumulatively explained $57.5 \%$ of the total variance. Assessment of the correlation and component matrices suggested that the items in the scale were strong and thus, none were removed. 


\section{Finalizing the Risk Assessment Tool}

The final risk assessment tool was also informed by field-based recommendations including additional questions, item rewording, assessment reordering, and scoring clarification provided by the risk assessors. For example, the Financial Abuse scale began with 15 items and ended up with 16 items (as indicated in Table 2), despite one item having been removed as a result of the PCA analysis. Two additional questions were then added based on risk assessor feedback. The final tool integrated two significant modifications from the suggestions of risk assessors. First, the 20-item CES-D scale was replaced by the abbreviated 10-item CESD-R (Van Dam \& Earleywine, 2011) as clients often found the CES-D questions redundant. Second, a seven-item Technology Abuse scale was also added as the risk assessors noted the new type of abuse experienced by survivors. The Cyber Dating Abuse Scale is a relatively new instrument that captures how a perpetrator can use technology to further intimidate the partner (Zweig et al., 2014). Due to the overlap of items with the Stalking scale, the research team removed the item "Sent you unwanted emails, instant messages, or sent messages through websites like Facebook, Snapchat, or Instagram." According to the feedback from risk assessors, such a standardized tool was beneficial to decrease the subjective nature of risk assessment and to improve the assessment process.

Risk assessors shared that the partner risk, partner access, and perception of safety questions, along with the open-ended questions, provided important background information to guide them when making waiver recommendations for clients whose scores indicate a moderate to high level of risk. The new tools intended to provide guidance on which waivers would be most appropriate for a client given their current situation, addressing a concern of focus group participants that previously waivers were granted on an "all or nothing" basis, meaning that clients were typically granted either all waivers or none at all. The more targeted approach of waiver recommendations in the new risk and impact assessment process received positive feedback.

The final tool, made up of a total of 95 items, named the New Jersey Assessment of Domestic Violence Risk and Impact (NJADVRI), is available in its entirety for use by other states and can be found within Postmus et al. (2017).

\section{Strengths and Limitations}

This project had several strengths as well as several limitations. Some strengths include the use of triangulated methods to gather information from a range of sources about the gaps in the FVO process and needs both nationally and in New Jersey. Moreover, some validated measures were included in the scales, which allowed for the use of quantitative analysis to reduce items where possible to promote efficiency and thoroughness of the assessment. Furthermore, the researchers had the opportunity to develop and then pilot the instrument. This provided an opportunity to both identify and remedy challenges that emerged and assure the development of a comprehensive assessment based on feedback from both DV advocates, county welfare workers, and state human services organization representatives. Further, this study provided social workers with expertise in DV the opportunity to be directly involved in the shaping of FVO policies and practices in New 
Jersey. Finally, the assessment uses quantitative and qualitative information to comprehensively assess a client's situation and is the first step towards standardizing a risk assessment tool for survivors of DV seeking waivers as part of the FVO process.

However, there were some limitations to the project that are important to acknowledge. The finalized instrument was not validated. Moreover, an investigation of how the final tool was implemented across the state was beyond the scope of this particular study. As a next step, researchers should conduct a similar study by collecting completed revised risk assessments from risk assessors and evaluating the scoring process. Furthermore, data collection for the instrument occurred in only one state so the information collected as part of survey development is not generalizable to other states. Finally, the researchers do not know whether the clients received the waivers recommended by the risk assessors.

A potential limitation of the risk assessment instrument itself is that it takes approximately 45 to 60 minutes to complete. The research team felt it was important to capture the nuanced nature of the risk and impact of DV through a comprehensive tool that included both closed-ended and open-ended questions. Preliminary feedback from the risk assessors suggested that this tool was easy to administer and score, thus serving as an improvement upon the instrument previously used which took even longer to complete. Further, in order to complete the assessment, clients were required to schedule an appointment in advance and the DV organizations tried to eliminate hardships for survivors during this process by providing transportation and childcare, when able. However, it is possible that the tool could cause fatigue in clients.

\section{Policy, Practice, and Research Implications}

To improve FVO utilization and survivor outcomes, a standardized, yet flexible, tool is critical to assess risk and impact among survivors. In order to accomplish this goal and advance significant policy change in this area, a diverse collaborative effort among the state-level administrators who sponsored the research and university researchers was necessary. The project depended on and greatly benefitted from participation by staff from county welfare agencies, DV organizations, state human services organization representatives, as well as from survivors. As such, this study also describes ways in which scholars from social work and public policy can influence the policy arena by utilizing evidence-informed methodologies that prioritize practice-wisdom.

While validated evidence and primary qualitative and quantitative research were critical components of building and testing the tool, the feasibility and strength of the tool also depended firmly on the incorporation of frontline practice wisdom through informal feedback from the risk assessors. Moreover, the incorporation of practitioner viewpoints and collaboration with administrators supported the ultimate utilization of the tool and policy change. This allowed both policymakers, DV advocates, and county welfare practitioners to tackle the FVO policy challenges by helping adapt, create, and implement a robust and standardized tool assess risk among applicants. This tool enables workers to make informed decisions about which cases to offer waivers of good cause, as mandated by the statute of the FVO policy itself. The collaboration behind the project resulted in a strong and feasible change to the FVO policy in New Jersey. 
Based on this process and experience, we recommend that other states seeking changes explore partnerships with researchers in order to make decisions informed by best practices and systematic research. In our work on the risk assessment tool, we also found that facilitating and formalizing relationships between welfare caseworkers and DV advocates could be important in creating and sustaining practice improvements. A siloed approach to roles and responsibilities thwarts program improvements that cross departments and agencies. Cross-training on DV and welfare for both FVO screeners and risk assessors would likely improve the policy's efficacy. Allowing for some flexibility within a formalized tool and assessment process is important in meeting the unique needs of individual survivors. This flexibility exacerbates the need for training and means that risk assessors should have a strong understanding and comfort level with working with survivors as well as a strong understanding of the policies and procedures that dictate those working in welfare organizations.

Finally, the research team recommends that policy change is not thought of as a completed task. Considering the FVO risk assessment process specifically, tools and processes should be updated to reflect cultural and technological changes. Assessment tools should also be revisited periodically to determine if questions are still appropriate. The questions related to cyber stalking that were added to the final tool are good examples of the need to revisit tools over time. Policy makers and administrators must also assess confidentiality policies and practices, particularly in regard to data sharing and access.

\section{Suggestions for Future Research}

Additional research is needed that validates this risk assessment tool with the general welfare sample as well as with welfare organizations in other states. Such research should also include evaluation of the screening and identification processes as well as the longterm outcomes of those survivors who were recommended for, as well as received waivers. More research is also needed which explores the scoring process for this revised risk assessment tool to test and explore whether the NJADVRI adequately identifies the risk and impact of current and future abuse. Further research could also examine whether survivors desire the suggested waivers. Finally, additional research could explore, what role, if any, that survivors play in determining which waivers are needed or wanted. Research must disentangle the perceptions of safety and risk by survivors compared to the findings from the risk assessment tool itself.

\section{References}

Abdi, H., \& Williams, L. J. (2010). Principal component analysis. Wiley Interdisciplinary Reviews: Computational Statistics, 2(4), 433-459. doi: https://doi.org/10.1002/wics.101

Allard, M. A., Albelda, R., Colten, M. E., \& Cosenza, C. (1997). In harm's way? Domestic violence, AFDC receipt, and welfare reform in Massachusetts. Boston: University of Massachusetts, McCormack Institute and Center for Survey Research.

An, S., Yoo, J., \& Nackerud, L. G. (2016). Using game theory to understand screening for domestic violence under the TANF family violence option. Advances in Social Work, 16(2), 338-357. doi: https://doi.org/10.18060/16671 
Barusch, A., Taylor, M. J., \& Derr, M. (1999). Understanding families with multiple barriers to self-sufficiency. Salt Lake City: University of Utah, Social Research Institute.

Bonomi, A. E., Thompson, R. S., Anderson, M., Reid, R. J., Carrell, D., Dimer, J. A., \& Rivara, F. P. (2006). Intimate partner violence and women's physical, mental, and social functioning. American Journal of Preventive Medicine, 30(6), 458-466. doi: https://doi.org/10.1016/j.amepre.2006.01.015

Braun, V., \& Clarke, V. (2006). Using thematic analysis in psychology. Qualitative Research in Psychology, 3(2), 77-101. doi: https://doi.org/10.1191/1478088706qp063oa

Campbell, J. C. (1995). Assessing dangerousness: Violence by sexual offenders, batterers, and child abusers. NY: Sage.

Campbell, J. C. (2004). Helping women understand their risk in situations of intimate partner violence. Journal of Interpersonal Violence, 19(12), 1464-1477. doi: https://doi.org/10.1177/0886260504269698

Campbell, J. C., Webster, D. W., \& Glass, N. (2009). The danger assessment: Validation of a lethality risk assessment instrument for intimate partner femicide. Journal of Interpersonal Violence, 24(4), 653-674. doi: https://doi.org/10.1177/0886260508317180

Casey, T., Davies, J., Gifford, A., \& Menard, A. (2010). Not enough: What TANF offers family violence victims. New York, NY: Legal Momentum and Harrisburg, PA: National Resource Center on Domestic Violence.

Carbone-López, K., Kruttschnitt, C., \& Macmillan, R. (2006). Patterns of intimate partner violence and their associations with physical health, psychological distress, and substance use. Public Health Reports, 121(4), 382-392. doi: https://doi.org/10.1177/003335490612100406

Cole, P. R. (2001). Impoverished women in violent partnerships: Designing services to fit their reality. Violence Against Women, 7(2), 222-233. doi: https://doi.org/10.1177/10778010122182415

Culbertson, K. A., Vik, P. W., \& Kooiman, B. J. (2001). The impact of sexual assault, sexual assault perpetrator type, and location of sexual assault on ratings of perceived safety. Violence Against Women, 7(8), 858-875. doi: https://doi.org/10.1177/10778010122182794

Echeburúa, E., Fernández-Montalvo, J., de Corral, P., \& López-Goñi, J. J. (2009). Assessing risk markers in intimate partner femicide and severe violence: A new assessment instrument. Journal of Interpersonal Violence, 24(6), 925-939. doi: https://doi.org/10.1177/0886260508319370

Ewing, J. (1984). Detecting alcoholism: The CAGE Questionnaire. Journal of the American Medical Association, 252(14), 1905-1907. doi: https://doi.org/10.1001/jama.252.14.1905 
Goodman, L. A., Smyth, K. F., Borges, A. M., \& Singer, R. (2009). When crises collide: How intimate partner violence and poverty intersect to shape women's mental health and coping? Trauma, Violence, \& Abuse, 10(4), 306-329. doi: https://doi.org/10.1177/1524838009339754

Hansen, M., Andersen, T. E., Armour, C., Elklit, A., Palic, S., \& Mackrill, T. (2010). PTSD-8: A Short PTSD Inventory. Clinical Practice and Epidemiology in Mental Health, 6, 101-108. doi: https://doi.org/10.2174/1745017901006010101

Hahn, S. A., \& Postmus, J. L. (2014). Economic empowerment of impoverished IPV survivors: A review of best practice literature and implications for policy. Trauma, Violence, \& Abuse, 15(2), 79-93. doi: https://doi.org/10.1177/1524838013511541

Hetling, A., Saunders, C., \& Born, C. E. (2006). "Missing" domestic violence victims in welfare caseloads: The discrepancy between administrative and survey disclosure rates. Journal of Health \& Social Policy, 22(2), 79-95. doi: https://doi.org/10.1300/j045v22n02_05

Holcomb, S., Johnson, L., Hetling, A., Postmus, J. L., Steiner, J., Braasch, L., \& Riordan, A. (2017). Implementation of the Family Violence Option 20 years later: A review of state welfare rules for domestic violence survivors. Journal of Policy Practice, 16(4), 415-431. doi: https://doi.org/10.1080/15588742.2017.1311820

Kropp, P. R. (2008). Intimate partner violence risk assessment and management. Violence and Victims, 23(2), 202-220. doi: https://doi.org/10.1891/0886-6708.23.2.202

Laakso, J. H., \& Drevdahl, D. J. (2006). Women, abuse, and the welfare bureaucracy. Affilia, 21(1), 84-96. doi: https://doi.org/10.1177/0886109905283135

Lein, L., Jacquet, S., Lewis, C., Cole, P., \& Williams, B. (2001). With the best of intentions: Family Violence Option and abused women's needs. Violence Against Women, 7(2) 193-210. doi: https://doi.org/10.1177/10778010122182398

Lindhorst, T., Meyers, M., \& Casey, E. (2008). Screening for domestic violence in public welfare offices: An analysis of a case manager and client interactions. Violence Against Women, 14(1), 5-28. doi: https://doi.org/10.1177/1077801207311948

Maiuro, R. D., Vitaliano, P. P., Sugg, N. K., Thompson, D. C., Rivara, F. P., \& Thompson, R. S. (2000). Development of a health care provider survey for domestic violence: Psychometric properties. American Journal of Preventive Medicine, 19(4), 245-252. doi: https://doi.org/10.1016/s0749-3797(00)00230-0

Meisel, J., Chandler, D., \& Rienzi, B. M. (2003). Domestic violence prevalence and effects on employment in two California TANF populations. Violence Against Women, 9(10), 1191-1212. doi: https://doi.org/10.1177/1077801203255861

Macmillan, R., Nierobisz, A., \& Welsh, S. (2000). Experiencing the streets: Harassment and perceptions of safety among women. Journal of Research in Crime and Delinquency, 37(3), 306-322. doi: https://doi.org/10.1177/0022427800037003003 
Marshall, L. L. (1992). Development of the Severity of Violence Against Women Scale. Journal of Family Violence, 7, 103-121.

Meier, J. (1997). Domestic violence, character, and social change in the welfare reform debate. Law \& Policy, 19(2), 205-263. doi: https://doi.org/10.1111/1467-9930.00028

Messing, J. T., \& Thaller, J. (2014). Intimate partner violence risk assessment: A primer for social workers. British Journal of Social Work, 45(6), 1804-1820. doi: https://doi.org/10.1093/bjsw/bcu012

Monahan, J., \& Skeem, J. L. (2014). The evolution of violence risk assessment. CNS spectrums, 19(5), 419-424. doi: https://doi.org/10.1017/s1092852914000145

Nicholls, T. L., Pritchard, M. M., Reeves, K. A., \& Hilterman, E. (2013). Risk assessment in intimate partner violence: A systematic review of contemporary approaches. Partner Abuse, 4(1), 76-168. doi: https://doi.org/10.1891/1946-6560.4.1.76

Osborne, J. W., \& Costello, A. B. (2004). Sample size and subject to item ratio in principal components analysis. Practical Assessment, Research \& Evaluation, 9(11), 1-9. Retrieved from https://pareonline.net/getvn.asp? $\mathrm{n}=11 \& \mathrm{v}=9$

Personal Responsibility and Work Opportunity Reconciliation Act of 1996, P. L. 104193, 110 Stat. 2105 (1996).

Postmus, J. L. (2000). Analysis of the Family Violence Option: A strengths perspective. Affilia, 15(2), 244-258. doi: https://doi.org/10.1177/08861090022093967

Postmus, J. L. (2004). Battered and on welfare: The experiences of women and the family violence option. Journal of Sociology and Social Welfare, 31(2), 113-123.

Postmus, J. L., Hetling, A., Johnson, L., Steiner, J., Lin, H., \& Holcomb, S. (2017). New Jersey Assessment of Domestic Violence Risk and Impact (NJADVRI). Retrieved from https://socialwork.rutgers.edu/centers/center-violence-against-women-andchildren/research-and-evaluation/assessingdomestic-violence-under-family-violenceoption-fvo

Postmus, J. L., Plummer, S., \& Stylianou, A. M. (2016). Measuring economic abuse in the lives of survivors: Revising the Scale of Economic Abuse. Violence Against Women, 22(6), 692-703. doi: https://doi.org/10.1177/1077801215610012

Postmus, J. L., Stylianou, A. M., \& McMahon, S. (2016). The Abusive Behavior Inventory - Revised. Journal of Interpersonal Violence, 31(17), 2867-2888. doi: https://doi.org/10.1177/0886260515581882

Radloff, L. S. (1977). The CES-D Scale: A self-report depression scale for research in the general population. Applied Psychological Measurement, 1, 385-401. doi: https://doi.org/10.1177/014662167700100306

Saunders, D. G., Holter, M. C., Pahl, L. C., Tolman, R. M., \& Kenna, C. E. (2005). TANF workers' responses to battered women and the impact of brief worker training: 
What survivors report. Violence Against Women, 11(2), 227-254. doi: https://doi.org/10.1177/1077801204271837

Spitzer, R. L., Kroenke, K., Williams, J. B., \& Lowe, B. (2006). A brief measure for assessing generalized anxiety disorder: The GAD-7. Archives of Internal Medicine, 166(10), 1092-1097. doi: https://doi.org/10.1001/archinte.166.10.1092

Stansfield, R., \& Williams, K. R. (2014). Predicting family violence recidivism using the DVSI-R: Integrating survival analysis and perpetrator characteristics. Criminal Justice and Behavior, 41(2), 163-180. doi: https://doi.org/10.1177/0093854813500776

Storey, J. E., Kropp, P. R., Hart, S. D., Belfrage, H., \& Strand, S. (2014). Assessment and management of risk for intimate partner violence by police officers using the Brief Spousal Assault Form for the evaluation of risk. Criminal Justice and Behavior, 41(2), 256-271. doi: https://doi.org/10.1177/0093854813503960

Streiner, D., Norman, G., \& Cairney, J. (2015). Health measurement scales: A practical guide to their development and use (5th ed.). Oxford, United Kingdom: Oxford University Press. doi: https://doi.org/10.1002/wmh3.140

Tabachnick, B. G., \& Fidell, L. S. (2013). Using multivariate statistics $\left(6^{\text {th }}\right.$ ed.). Boston: Allyn \& Bacon/Pearson Education.

Thompson, M. P., Basile, K. C., Hertz, M. F., \& Sitterle, D. (2006). Measuring intimate partner violence victimization and perpetration: A compendium of assessment tools. Atlanta, GA: Centers for Disease Control and Prevention, National Center for Injury Prevention and Control.

Tolman, R. M., \& Raphael, J. (2000). A review of research on welfare and domestic violence. Journal of Social Issues, 56(4), 655-682. doi: https://doi.org/10.1111/0022$\underline{4537.00190}$

U.S. Census Bureau. (2015). ACS demographic and housing estimates, 20112015 American community survey 5-year estimates. Retrieved from https://factfinder.census.gov/faces/tableservices/jsf/pages/productview.xhtml?src=bk $\underline{\mathrm{mk}}$

U.S Centers for Disease Control and Prevention. (2010). The national intimate partner and sexual violence survey (NISVS). Atlanta, GA: National Center for Injury Prevention and Control, Centers for Disease Control and Prevention. Retrieved from https://www.cdc.gov/violenceprevention/pdf/cdc_nisvs_ipv_report_2013_v17_single a.pdf

Van Dam, N. T., \& Earleywine, M. (2011). Validation of the Center for Epidemiologic Studies Depression Scale-Revised (CESD-R): Pragmatic depression assessment in the general population. Psychiatry Research, 186(1), 128-132. doi: https://doi.org/10.1016/j.psychres.2010.08.018 
Zweig, J. M., Dank, M., Lachman, P., \& Yahner, J. (2014). Technology, teen dating violence and abuse, and bullying: Final Report July 2013. Washington, DC: Urban Institute.

Author note: Address correspondence to: Jordan Steiner, MA, MSW, LSW, Doctoral Candidate, Rutgers School of Social Work, New Brunswick, NJ 08901. Email: jisteiner@gmail.com

Acknowledgements: The authors would like to thank the advocates, county welfare workers, state human services organization representatives, and survivors who took part in the research for this project. We are in their debt. Additionally, this project was supported by the New Jersey Department of Human Services, Division of Family Development. Points of view in this document are those of the authors and do not necessarily represent the official position or policies of the Department. 